(c) American Dairy Science Association, 2004.

\title{
Short Communication: Diurnal Profiles of Conjugated Linoleic Acids and Trans Fatty Acids in Ruminal Fluid from Cows Fed a High Concentrate Diet Supplemented with Fish Oil, Linseed Oil, or Sunflower Oil
}

\author{
J. J. Loor, ${ }^{\star}$ K. Ueda,† A. Ferlay, Y. Chilliard, and M. Doreau \\ Unité de Recherches sur les Herbivores INRA-Theix, \\ 63122 St.- Genès Champanelle, France
}

\begin{abstract}
Trans-18:1 and 18:2 isomer composition in ruminal fluid during the daily feeding cycle was examined in 3 cows fed a high concentrate diet (35:65) with $5 \%$ (DM basis) sunflower oil (SO), $5 \%$ linseed oil (LO), or $2.5 \%$ fish oil (FO) in a $3 \times 3$ Latin square with 34 -wk periods. Grass hay and concentrate mixtures were fed at 0900, 1300 , and $1700 \mathrm{~h}$ daily. Ruminal fluid was collected at 0900, 1100, 1300, 1500, 1700, 2000, and 0000 h. Feeding SO resulted in the greatest mean concentrations (\% of total fatty acids) of trans 10, cis 12-18:2 and cis9,trans1118:2. In particular, trans10,cis12-18:2 with SO was greater at $1500(0.29 \%), 2000(0.34 \%)$, and $0000 \mathrm{~h}$ $(0.25 \%)$ relative to $0900 \mathrm{~h}(0.07 \%)$. Cis 9 ,trans $11-18: 2$ concentration increased from $0.47 \%$ at $0900 \mathrm{~h}$ to a peak of $2.06 \%$ at $1100 \mathrm{~h}$; it remained greater than the percentage determined at $0900 \mathrm{~h}$ at $1300(1.4 \%)$ through $0000 \mathrm{~h}(1.1 \%)$. Concentration of trans 11,cis $15-18: 2$ was greatest with LO, ranging from $3.3 \%(0900 \mathrm{~h})$ to a peak of $11.4 \%$ at $2000 \mathrm{~h}$. Mean trans $10-18: 1$ concentration ranked by diet was $\mathrm{SO}>\mathrm{FO}>\mathrm{LO}$. Peak trans 10-18:1 with SO was observed at $1700 \mathrm{~h}(14.9 \%)$ compared with $0900 \mathrm{~h}(5.1 \%)$. Trans11-18:1 did not differ with diet or time. Stearic acid decreased over time with all diets reaching minimum concentrations at 1700 to $2000 \mathrm{~h}$ relative to $0900 \mathrm{~h}$. Feeding FO, however, decreased mean 18:0 concentration 4-fold compared with LO or SO. The moderate effect on concentration of trans-18:1 coupled with accumulation of 18:2 intermediates and the decrease of 18:0 over time suggest that oils reduced the biohydrogenation of 18:2 isomers to trans-18:1.
\end{abstract}

(Key words: fish oil, linseed oil, sunflower oil, ruminal fatty acid)

\footnotetext{
Received April 6, 2004.

Accepted May 9, 2004.

Corresponding author: J. J. Loor; e-mail: jloor@uiuc.edu.

*Present address: Department of Animal Sciences, University of Illinois, 206 ERML, Urbana 61801.

$\dagger$ Present address: Graduate School of Agriculture, Hokkaido University, Sapporo, 060-8589, Japan.
}

Abbreviation key: CLA = conjugated linoleic acids, $\mathbf{F O}=$ fish oil, $\mathbf{L O}=$ linseed oil, $\mathbf{S O}=$ sunflower oil.

Vegetable or marine oils elevate the concentration and yield of conjugated linoleic acids (CLA) and transfatty acids in milk fat (Chilliard et al., 2001). Vaccenic acid, trans 10-18:1, cis9,trans11-18:2, and trans 10,cis12-18:2 are dramatically increased with high concentrate diets supplemented with polyunsaturated fatty acids (Bauman and Griinari, 2001) or mixed diets with fish oil (FO) (Chilliard et al., 2001). Trans10,cis12-18:2 and trans10-18:1 have been implicated in diet-induced milk fat depression (Bauman and Griinari, 2001).

Loor et al. (2002) presented the first detailed composition of trans-18:1, cis-18:1, nonconjugated 18:2, and some CLA in ruminal fluid from dairy cows fed canola or soybean oil. AbuGhazaleh et al. (2002) reported profiles of some 18:1 and 18:2 isomers in ruminal digesta from cows fed FO. Results from both studies corresponded to a single time point after feeding. AbuGhazaleh and Jenkins (2004ab) recently examined aspects of biohydrogenation of pure 20:5n-3 and 22:6n-3 administered as a single dose to batch cultures during 24-h incubations. Identification of key trans-18:1, non-conjugated 18:2, and CLA isomers during the daily feeding cycle could be used to evaluate the production of intermediates from different polyunsaturated oils with less risk of bias (e.g., acid accumulation) than in vitro. To examine this premise, we took advantage of a study that was primarily designed to assess ruminal digestion and production responses in cows fed a high concentrate diet plus FO, linseed oil (LO), or sunflower oil (SO) (Ueda et al., 2003). We identified 5 cis-18:1, cis9through cis 15 -; 10 trans-18:1, trans4- through trans 16 -; 7 nonconjugated 18:2 isomers; 8 CLA isomers; and 4 18:3 isomers in ruminal fluid. All of these isomers were identified in duodenal contents, and most were increased by high dietary concentrate:forage (cis- and trans-18:1 primarily), LO (most 18:1, 18:2, and 18:3 isomers), or their interaction (Loor et al., 2004). 
Three peak lactation multiparous Holstein cows (71 \pm 16 DIM) were fed a diet with $65 \%$ concentrate (based on ground wheat, soybean meal, and rapeseed meal) and $35 \%$ forage (long-cut grass hay) supplemented with FO (2.5\% of DM), SO (5\%), or LO (5\%) (Huilerie Van de Putte, Mouscron, Belgium) in a $3 \times 3$ Latin square design during 34 -wk periods. The level of FO was chosen to avoid detrimental effects on DMI (Chilliard et al., 2001). Grass hay and concentrate mixtures were fed separately in 3 meals at 0900, 1300, and $1700 \mathrm{~h}$ daily. Ruminal fluid ( $300 \mathrm{~mL}$ ) was collected during wk 4 by suction from the ventral sac via the ruminal cannula at $0900,1100,1300,1500,1700,2000$, and 0000 h. Ruminal $\mathrm{pH}$ was recorded using these samples, but no diet $(6.42 \pm 0.05)$ or diet by time effects were observed $(P>0.39)$. However, $\mathrm{pH}$ decreased $(P<0.05)$ between 1100 through $0000 \mathrm{~h}$ relative to $0900 \mathrm{~h}$ regardless of diet. Dry matter intake and milk yield did not differ because of treatments $(17.9 \pm 2.4$ and $26.0 \pm 6.8 \mathrm{~kg} / \mathrm{d})$. Milk fat percentage also was not affected $(P>0.50)$ by $\operatorname{diet}(2.64 \pm 0.36)$. Methylation and identification of fatty acids was conducted as described by Loor et al. (2004). Methyl esters were separated on a $100-\mathrm{m} \times 0.25$-mm i.d. fused-silica capillary column (CP-Sil 88; Chrompack, Middelburg, The Netherlands) using a Varian CP-3800 GC (Varian, Les Ulis, France). Data were analyzed as a Latin square with repeated measures using the MIXED procedure of SAS (SAS Inst. Inc., Cary, NC). Differences caused by diet, time, diet by time interactions, linear contrasts, and differences between means at 1100 , $1300,1500,1700,2000$, and $0000 \mathrm{~h}$ relative to $0900 \mathrm{~h}$ were considered to be significant when $P \leq 0.05$.

The test oils changed concentrations of trans-18:1 and 18:2 (conjugated and nonconjugated) isomers without $(P>0.05)$ affecting total fatty acid concentration (34.5 $\pm 3.3 \mathrm{mg} / \mathrm{g}$ fluid DM). Cis9,trans11-18:2 was the most predominant CLA regardless of diet, and mean concentration was greater $(P<0.05)$ with SO $(1.46$ vs. $0.72 \mathrm{mg} / \mathrm{g}$ ) compared with FO or LO (Figure 1A). The concentration of this isomer was 4.5 -fold greater $(P<$ $0.05)$ at $1100 \mathrm{~h}$ and 4.3 -fold greater $(P<0.05)$ at 1500 $\mathrm{h}$ compared with $0900 \mathrm{~h}$, suggesting active biohydrogenation of substrate after the 0900 - and 1300 -h feeding or a lag time effect. The overall correlation $(\mathrm{n}=63)$ between 18:2n-6 and cis9,trans11-18:2 was 0.54 , and that between cis9,trans11-18:2 and trans11-18:1 was 0.26 . The low correlation between this CLA and trans11-18:1 is likely due to the fact that trans11-18:1 could originate from cis9,trans11-18:2, trans11,cis1518:2, and(or) other 18:1 isomers (Mosley et al., 2002; Proell et al., 2002). The 18:2 isomers accumulated to different extents depending on diet fed (Figure 1, A and $\mathrm{B})$.
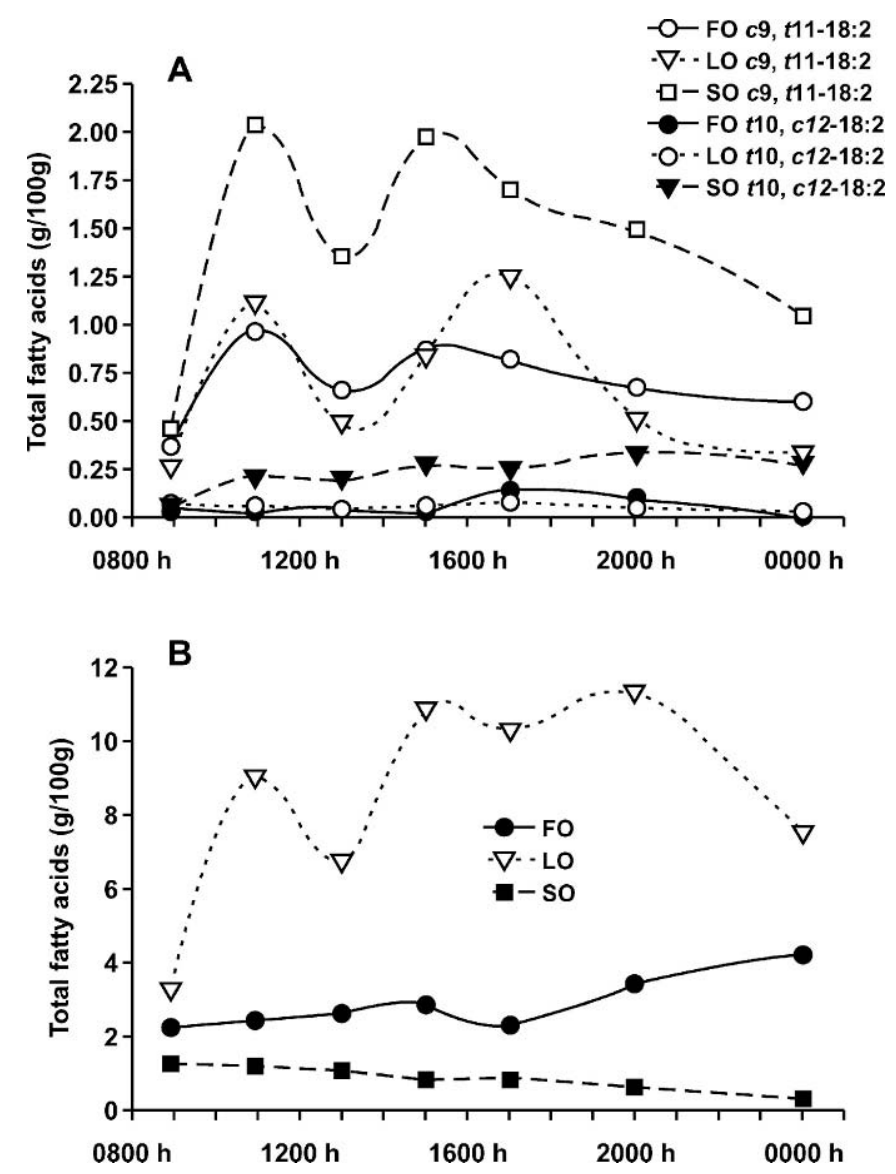

Figure 1. Diurnal pattern of cis $(c)$ 9,trans $(t)$ 11-18:2 $(\mathrm{SEM}=0.41)$ and $t 10, c 12$ to $18: 2(\mathrm{SEM}=0.06)($ Panel $\mathrm{A})$ or $t 11, c 15-18: 2(\mathrm{SEM}=$ 1.7) (Panel B) in mixed ruminal fluid. Feeding was at 0900,1300 , and $1700 \mathrm{~h}$ daily. $\mathrm{FO}=$ fish oil, $\mathrm{LO}=$ linseed oil, and $\mathrm{SO}=$ sunflower oil.

Concentration of trans 10,cis 12-18:2 was nearly undetectable at $0900 \mathrm{~h}$ regardless of diet (Figure 1A). However, it increased $(P<0.05)$ steadily with SO through $2000 \mathrm{~h}$ after which it declined slightly. This resulted in greater $(P<0.05)$ concentrations at $1100(0.21 \%)$, $1300(0.22 \%), 1500(0.29 \%), 2000(0.34 \%)$, and $0000 \mathrm{~h}$ $(0.25 \%)$ relative to $0900 \mathrm{~h}$. Feeding SO led to greater $(P<0.05)$ mean trans10,cis 12-18:2 concentration $(0.23$ vs. $0.07 \mathrm{mg} / \mathrm{g} \mathrm{DM}$ ) compared with other diets, but this isomer remained a minor one. The correlation between 18:2n-6 and trans 10 , cis $12-18: 2$ with SO was 0.72 , which may suggest that a portion of dietary $18: 2 n-6$ was isomerized to this CLA, as proposed by Bauman and Griinari (2001).

There was a significant $(P=0.05)$ diet by time interaction for the concentration of trans11,cis 15-18:2 (Figure $1 B)$, resulting from the gradual increase in production of this isomer primarily with $\mathrm{LO}$ and to a smaller extent with FO. Feeding FO resulted in an increase $(P<0.05)$ in trans11,cis15-18:2 that followed an overall linear 
trend, although concentrations at 1100 through 0000 $\mathrm{h}$ relative to $0900 \mathrm{~h}$ were not statistically significant $(P$ $>0.20$ ). With LO, concentrations at 1100 through 0000 $\mathrm{h}$ were 2.8 - to 3.5 -fold greater $(P<0.05)$ (Figure $1 \mathrm{~B})$. Mean concentration was markedly greater $(P<0.05)$ with LO (accounted for $68 \%$ of total nonconjugated 18:2) $(8.96 \mathrm{mg} / \mathrm{g})$ but also increased $(P<0.05)$ with $\mathrm{FO}(2.93$ $\mathrm{mg} / \mathrm{g})$ compared with SO $(0.95 \mathrm{mg} / \mathrm{g})$. This isomer is the major nonconjugated 18:2 produced during hydrogenation of 18:3n-3. We found an increase in the duodenal flow of this fatty acid in cows fed linseed oil compared with controls (Loor et al., 2004). A similar increase also was observed in omasal contents from cows fed FO (Shingfield et al., 2003). We hypothesize that FO resulted in incomplete biohydrogenation of $18: 3 n-3$ derived from the basal diet.

The correlation between trans10,cis12-18:2 and trans 10-18:1 when SO was fed was 0.58 . This positive relationship may indicate that a portion of trans 10-18:1 was produced via the trans10,cis12-18:2 isomer (Loor and Herbein, 2001). Mean trans10-18:1 increased $(P<$ 0.05 ) with FO and SO (8.30 vs. $3.1 \mathrm{mg} / \mathrm{g}$ ) (Figure $2 \mathrm{~A}$ ), which was unexpected for $\mathrm{FO}$ based on previous data (Shingfield et al., 2003). However, those data were obtained in cows fed mixed diets (60:40 forage to concentrate) and may emphasize the importance of high dietary concentrate (Piperova et al., 2002; Loor et al., 2004 ) for ruminal accumulation of trans 10-18:1. Concentration of trans 10-18:1 with SO was 2.9-fold greater $(P=0.05)$ at 1700 than $0900 \mathrm{~h}$, but with FO it was 2.2 fold lower $(P<0.05)$ (Figure 2A). Concentrations of 20:5n-3, 22:6n-3, trans,trans-CLA, cis8,trans10-CLA, and trans 15-18:1 at $1700 \mathrm{~h}$ with FO were 3 - to 13 -fold greater $(P<0.05)$ relative to $0900 \mathrm{~h}$ (data not shown). This can, in part, explain the low concentrations of trans 10-18:1 and trans11-18:1 with FO at $1700 \mathrm{~h}$ (Figure 2, A and B). Greater trans 10-18:1 with FO (Figure 2A) was not associated with linoleic acid intake. The ratio (data not shown) of trans10-18:1 to trans11-18:1 with $\mathrm{FO}$ was 2.1 at $0900 \mathrm{~h}$ then decreased $(P=0.05)$ to $1.1-1.4$ at $1100 \mathrm{~h}$ through $0000 \mathrm{~h}$. It could be possible that as trans11-18:1 accumulated, a portion was converted to trans10-18:1. Several trans-18:1 were formed from ${ }^{13} \mathrm{C}$-trans 9-18:1 when incubated in vitro (Proell et al., 2002). Overall, diets did not $(P>0.05)$ affect trans 11 18:1 concentration.

The pattern of 18:0 concentration over time (Figure $2 \mathrm{C}$ ) indicated that all diets resulted in incomplete biohydrogenation during the feeding cycle. Concentration at 1500 through $0000 \mathrm{~h}$ was lower $(P<0.05)$ relative to $0900 \mathrm{~h}$ with all diets. Among treatments, however, feeding FO resulted in lower $(P<0.05) 18: 0$ at $0900 \mathrm{~h}$ and in lower $(P<0.05)$ overall mean 18:0 concentration $(11.9$ vs. $25.0 \mathrm{mg} / \mathrm{g})$. There was a negative correlation
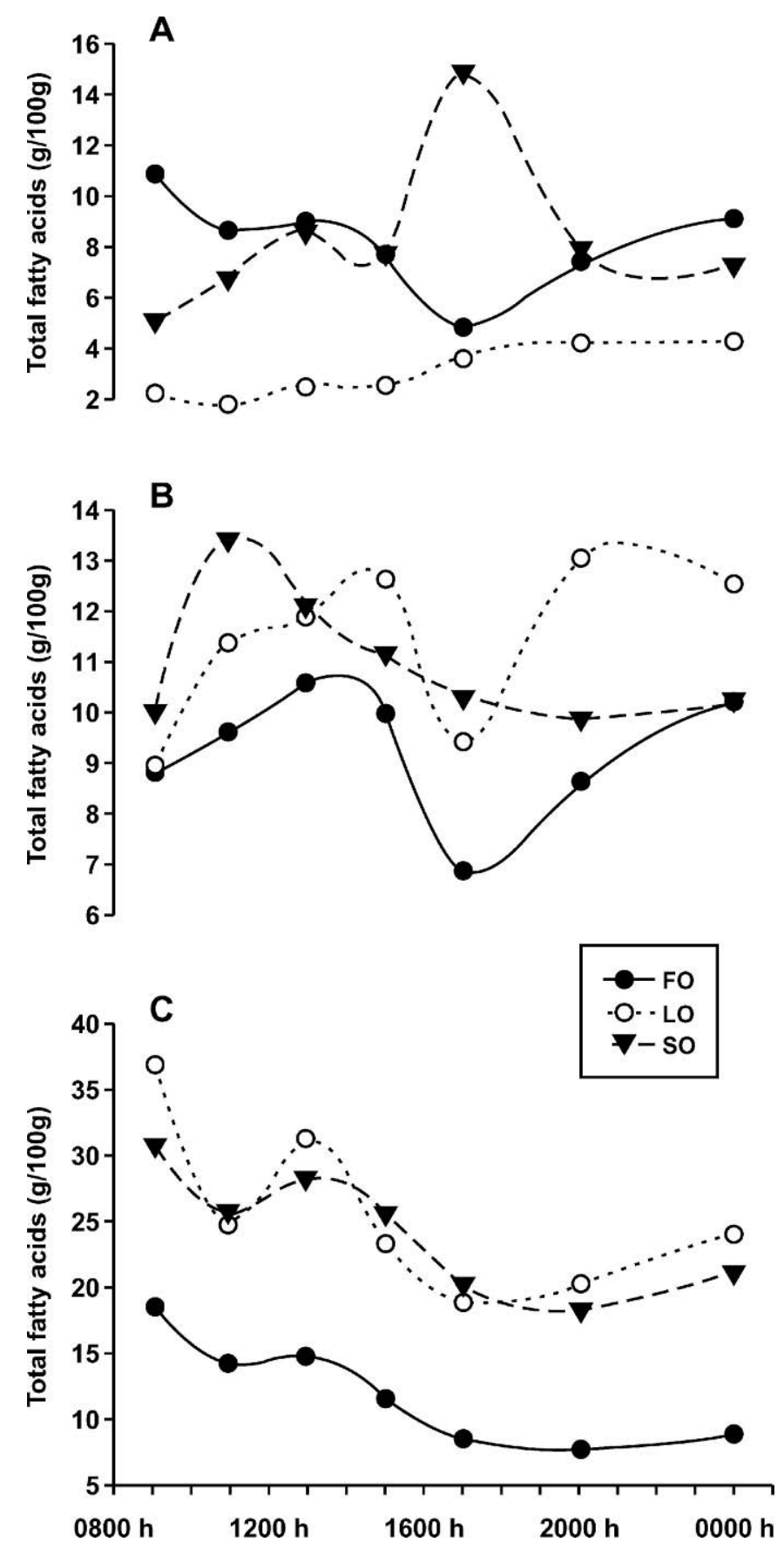

Figure 2. Diurnal pattern of trans10-18:1 (SEM = 2.3; Panel A), trans11-18:1 $(\mathrm{SEM}=3.0 ;$ Panel B $)$, and 18:0 $(\mathrm{SEM}=4.4$; Panel C) in mixed ruminal fluid. Feeding was at 0900,1300 , and $1700 \mathrm{~h}$ daily. FO = fish oil, LO = linseed oil, and $\mathrm{SO}=$ sunflower oil.

( $\mathrm{r}=-0.79$ ) between the concentration of $20: 5 n-3$ and 22:6n-3 with FO and 18:0 in ruminal fluid, suggesting that these fatty acids at very low concentrations ( 2 to $3 \%$ of total fatty acids in fluid) depress ruminal biohydrogenation of unsaturated fatty acids in the basal diet. 
Although speculative, it could be possible that the greater $(P<0.05)$ concentration of ruminal entodinium spp. that we found with FO (Ueda et al., 2003) may have, to some degree, caused the loss of bacteria carrying out the reduction of trans-18:1-18:0. Such response could account for the marked increase in milk trans-18:1 observed in cows fed mixed diets plus various levels of FO (Chilliard et al., 2001).

In summary, production of cis9,trans 11-18:2, trans10,cis 12-18:2, and trans10-18:1 was enhanced with SO containing high linoleic acid as a substrate for hydrogenation; whereas, LO enhanced production of trans11,cis15-18:2 from supplemental 18:3n-3. Fish oil resulted in a drastic reduction in 18:0 while increasing trans 10-18:1. The pattern of 18:0 concentration over time coupled with a moderate effect on the concentration of trans10-18:1 and trans11-18:1 and the apparent accumulation of cis9,trans11-18:2 and trans11,cis1518:2 suggest that the diets might have reduced the biohydrogenation of both 18:2 isomers to trans-18:1.

\section{ACKNOWLEDGMENTS}

The authors express their sincere appreciation to A. Ollier and all staff members of Experimental FarmDairy Unit Les Cèdres for care and feeding of the cows, particularly, D. Roux and F. Anglard. The technical assistance of J. Chabrot during fatty acid analysis also is highly appreciated.

\section{REFERENCES}

AbuGhazaleh, A. A., and T. C. Jenkins. 2004a. Disappearance of docosahexaenoic and eicosapentaenoic acids from cultures of mixed ruminal microorganisms. J. Dairy Sci. 87:645-651.

AbuGhazaleh, A. A., and T. C. Jenkins. 2004b. Short communication: Docosahexaenoic acid promotes vaccenic acid accumulation in mixed ruminal cultures incubated with linoleic acid. J. Dairy Sci. $87: 645-651$.
AbuGhazaleh, A., D. J. Schingoethe, A. R. Hippen, K. F. Kalscheur, and L. A. Whitlock. 2002. Fatty acid profiles of milk and rumen digesta from cows fed fish oil, extruded soybeans or their blend. J. Dairy Sci. 85:2266-2276.

Bauman, D. E., and J. M. Griinari. 2001. Regulation and nutritional manipulation of milk fat: Low-fat milk syndrome. Livest. Prod. Sci. 70:15-29.

Chilliard, Y., A. Ferlay, and M. Doreau. 2001. Effect of different types of forages, animal fat or marine oils in cow's diet on milk fat secretion and composition, especially conjugated linoleic acid (CLA) and polyunsaturated fatty acids. Livest. Prod. Sci. 70:31-48.

Loor, J. J., A. B. P. A. Bandara, and J. H. Herbein. 2002. Characterization of $18: 1$ and 18:2 isomers produced during microbial biohydrogenation of unsaturated fatty acids from canola or soyabean oil in the rumen of lactating cows. J. Anim. Physiol. Anim. Nutr. (Berlin) 86:422-432.

Loor, J. J., and J. H. Herbein. 2001. Alterations in blood plasma and milk fatty acid profiles of lactating Holstein cows in response to ruminal infusion of a conjugated linoleic acid mixture. Anim. Res. 50:463-476.

Loor, J. J., K. Ueda, A. Ferlay, Y. Chilliard, and M. Doreau. 2004. Biohydrogenation, duodenal flow, and intestinal digestibility of trans fatty acids and conjugated linoleic acids (CLA) in response to dietary forage:concentrate ratio and linseed oil in dairy cows. J. Dairy Sci. 87:2472-2485.

Mosley, E. E., G. Powell, M. Riley, and T. C. Jenkins. 2002. Microbial biohydrogenation of oleic acid to trans isomers in vitro. J. Lipid Res. 43:290-296.

Piperova, L. S., J. Sampugna, B. Teter, K. Kalscheur, M. Yurawecz, Y. Ku, K. Morehouse, and R. A. Erdman. 2002. Duodenal and milk trans octadecenoic acid and conjugated linoleic acid (CLA) isomers indicate postabsorptive synthesis is the predominant source of cis9-containing CLA in lactating dairy cows. J. Nutr. 132:1235-1241.

Proell, J. M., E. E. Mosley, G. L. Powell, and T. C. Jenkins. 2002. Isomerization of stable isotopically labeled elaidic acid to cis and trans monoenes by ruminal microbes. J. Lipid Res. 43:2072-2076.

Shingfield, K., S. Ahvenjärvi, V. Toivonen, A. Ärölä, K. V. V. Nurmela, P. Huhtanen, and J. M. Griinari. 2003. Effect of dietary fish oil on biohydrogenation of fatty acids and milk fatty acid content in cows. Anim. Sci. 77:165-179.

Ueda, K., J. J. Loor, A. Ferlay, J. Chabrot, Y. Chilliard, and M. Doreau. 2003. Ruminal digestion in lactating dairy cows fed a high-concentrate diet supplemented with sunflower, linseed, or fish oil. Page 10 in Proc. 28th Conf. Gastrointestinal Function, Chicago, IL. NCAUR, US Department of Agriculture, Washington, DC. 